\title{
MyD88 Regulates LPS-induced NF-кB/MAPK Cytokines and Promotes Inflammation and Malignancy in Colorectal Cancer Cells
}

\author{
GUANGWEI ZHU ${ }^{1,2^{*}}$, ZHIBIN CHENG ${ }^{1,2^{*}}$, CHUNLIN LIN $^{1}$, ROBERT M. HOFFMAN $^{3,4}$, \\ YONGJIAN HUANG ${ }^{1}$, SHREE RAM SINGH ${ }^{5}$, WEI ZHENG ${ }^{1}$, SHUGANG YANG $^{1}$ and JIANXIN YE ${ }^{1,2}$ \\ ${ }^{1}$ Department of Gastrointestinal Surgery 2 Section, \\ The First Hospital Affiliated to Fujian Medical University, Fuzhou, P.R. China; \\ ${ }^{2}$ Key Laboratory of Ministry of Education for Gastrointestinal Cancer, \\ Fujian Medical University, Fuzhou, P.R. China; \\ ${ }^{3}$ AntiCancer, Inc., San Diego, CA, U.S.A.; \\ ${ }^{4}$ Department of Surgery, University of California, San Diego, CA, U.S.A.; \\ ${ }^{5}$ Basic Research Laboratory, National Cancer Institute, Frederick, MD, U.S.A.
}

\begin{abstract}
Background/Aim: Inflammation may play a role in cancer initiation and progression. The molecular mechanisms by which inflammation causes colorectal cancer, remains unclear. The present study investigated a signaling pathway that affects inflammation in colorectal cancer. Materials and Methods: SW480 cells, HCT116 cells, and cells with knockdown of myeloid differentiation 88 (MyD88), and forced expression of MyD88 were treated with lipopolysaccharide ( $L P S ; 1 \mu \mathrm{g} / \mathrm{ml}$ ). Inflammation-related mRNA expression was analyzed by the quantitative reverse transcription polymerase chain reaction and inflammatory cytokines were detected by western blotting. The enzymelinked immunosorbent assay (ELISA) was used to quantify inflammation-related cytokines in colorectal cancer cells. Cancer cell properties were evaluated using the woundhealing assay, transwell migration assay, transwell invasion assay, colony-formation assay, and CCK-8 assay. Results:
\end{abstract}

This article is freely accessible online.

*These Authors contributed equally to this study.

Correspondence to: Jian-Xin Ye, Department of Gastrointestinal Surgery 2 Section, The First Hospital Affiliated to Fujian Medical University, 20th, Chazhong Road, Fuzhou, Fujian 350005, P.R. China. Tel: +86 13809553280, e-mail: yejianxinfuyi@126.com and Shree Ram Singh, Basic Research Laboratory, National Cancer Institute, Frederick, MD, 21702, U.S.A. Tel: +1 3018467331, e-mail: singhshr@mail.nih.gov

Key Words: MyD88, NF-kB/MAPK, LPS, inflammatory, colorectal cancer.
LPS up-regulated mRNA and protein levels of inflammatory factors in colorectal cancer cells. Knockdown of MyD88 inhibited LPS-induced mRNA expression and inflammatory protein expression in colorectal cancer cells. Similarly, silencing of MyD88 expression suppressed LPS-induced changes in the biological behavior of colorectal cancer cells. Silencing of MyD88 expression down-regulated expression of proteins of the LPS/nuclear factor kappa-light-chainenhancer of activated B-cells $(N F-k B) / m i t o g e n-a c t i v a t e d$ protein kinase (MAPK) signaling pathway. Restoration of the expression of MyD88 reversed the effects in LPS-treated HCT116 cells. Conclusion: MyD88-regulated LPS/NF$\kappa B / M A P K$ signaling pathway affects the inflammatory and biological behavior of LPS-induced colorectal cancer cells.

Colorectal cancer is the fourth leading cause of cancerrelated death in the world and the fifth in China, with increasing incidence and mortality $(1,2)$. For more than two centuries, it has been known that inflammation and coexist. Some studies have indicated that inflammation promotes the progression of cancer (3-5). Long-term microbial infection may cause colorectal mucosa metaplasia, atypical hyperplasia and carcinoma in situ, finally leading to colorectal cancer $(6,7)$. However, the mechanisms by which inflammation promotes cancer progression remain unclear.

Lipopolysaccharide (LPS) is present in the cell wall of Gram-negative bacteria $(6,7)$. Gram-negative bacterial infection leads to release of LPS in colorectal tumors in situ. Previous studies have reported that LPS can promote cell migration, invasion and the epithelial-mesenchymal transition and contribute to the progression of cancer (8-10). LPS may contribute to metastasis by accelerating cell 
A

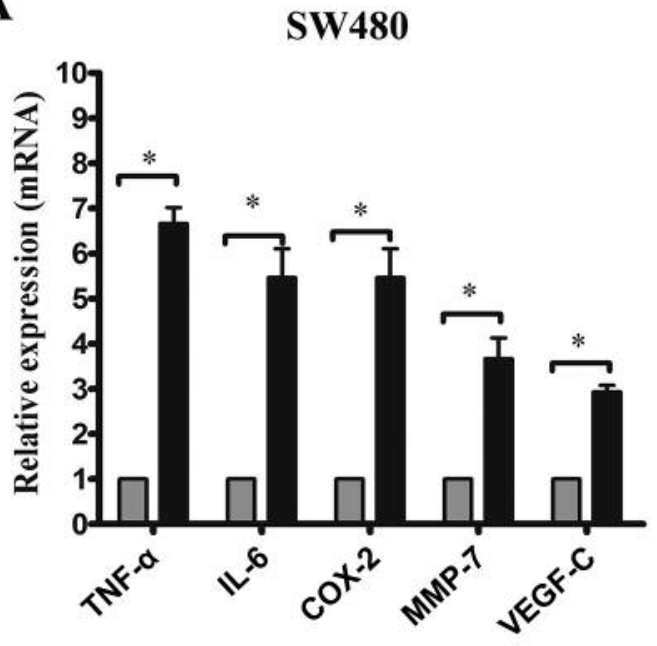

HCT116

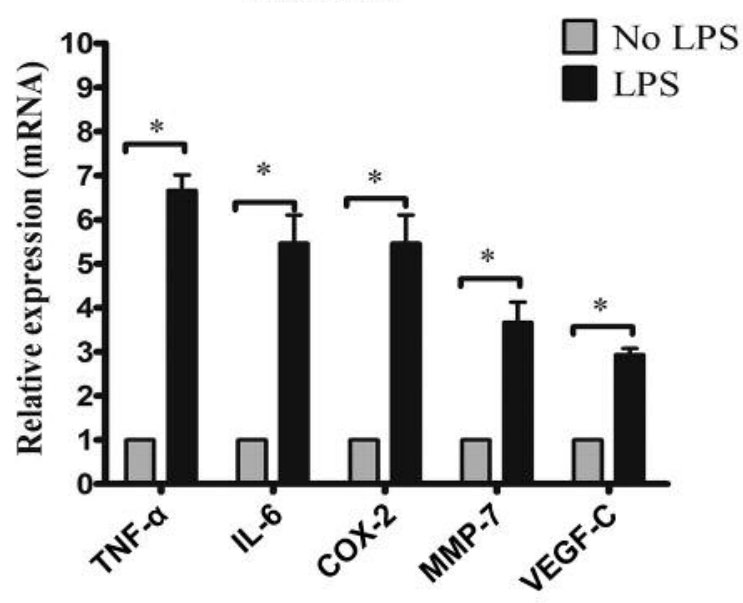

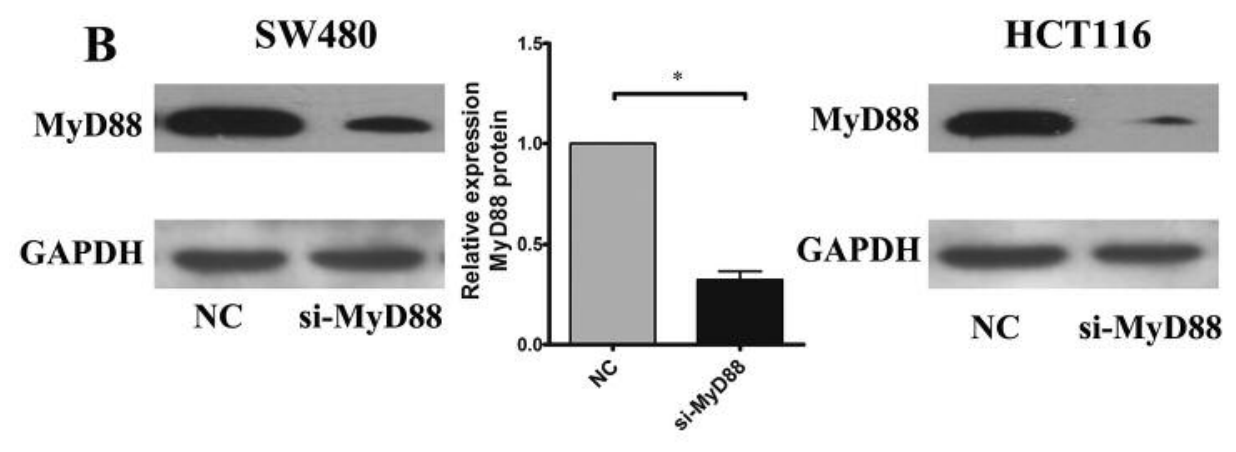
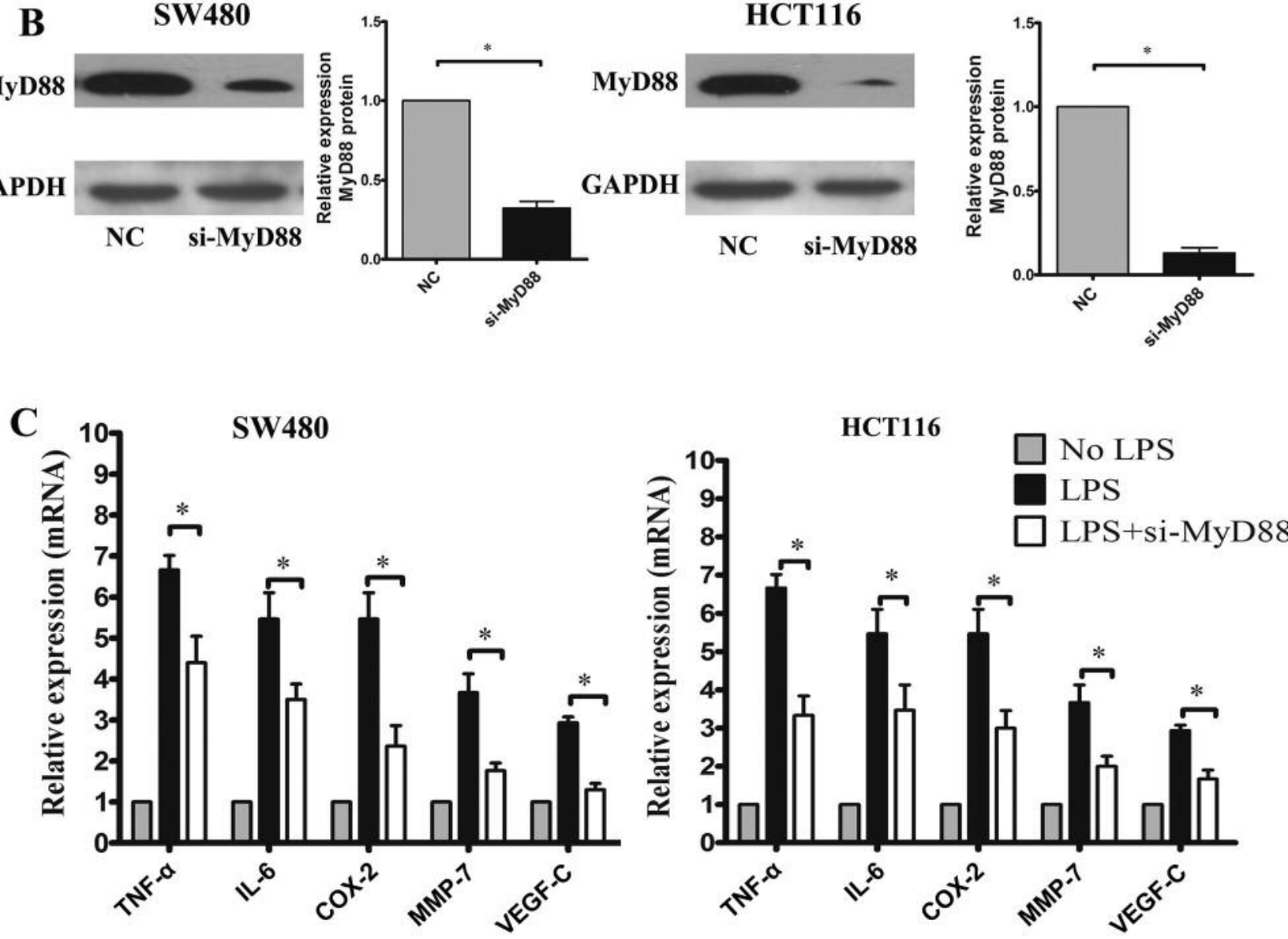

Figure 1. Knockdown of expression of MyD88 with small interfering RNA (si-MyD88) down-regulated the mRNA expression of inflammatory factors induced by lipopolysaccharide (LPS) in SW480 cells (left panel) and HCT116 cells (right panel). A: mRNA expression of tumor necrosis factor- $\alpha$ (TNF-a), interleukin 6 (IL-6), cyclo-oxygenase-2 (COX-2), matrix metallopeptidase-7 (MMP-7), MMP-10, and vascular endothelial growth factor$C(V E G F C)$ in parental cells treated with $1 \mu \mathrm{g}$ LPS in culture medium for $24 \mathrm{~h}$ compared to untreated cells. B: Western blot analysis of the expression of MyD88 protein in the negative control (NC) and SW480 and HCT116 cells with si-MyD88. C: Quantitative reverse transcription polymerase chain reaction analysis of mRNA expression of TNF-a, IL-6, COX-2, MMP-7, and VEGF-C in parental and si-MyD88 SW480 and si-MyD88 HCT116 cells treated with $1 \mu \mathrm{g}$ LPS for 24 h compared to untreated cells. *Significantly different at $p<0.05$. 
motility, invasiveness and survival $(11,12)$. Infection can trigger a cascade of inflammatory responses mediated by various inflammatory cell types that are involved in cancer progression, these includes tumor necrosis factor- $\alpha$ (TNF- $\alpha$ ), interleukin 6 (IL-6), cyclooxygenase-2 (COX-2), matrix metallopeptidase-7 (MMP-7), MMP-10, and vascular endothelial growth factor-C (VEGF-C).

LPS binding to toll-like receptor-4 can activate myeloid differentiation 88 (MyD88)-dependent and MyD88independent signaling pathways, which promote the production of inflammatory factors (13). MyD88-deficient mice were shown to be resistant to LPS-induced septic shock, and MyD88-deficient macrophages failed to produce pro-inflammatory cytokines after LPS stimulation (14) Signaling by nuclear factor kappa-light-chain-enhancer of activated B-cells (NF-kB) promotes inflammation and cell proliferation through induction of inflammatory cytokines (15). The ability of MyD88 to signal through NF-kB suggests that NF-kB-dependent signaling is also important in inflammation.

In the present report, we investigated MyD88 regulation of LPS-induced inflammatory cytokines in migration and invasion of colorectal cancer cells.

\section{Materials and Methods}

Cell culture. The human colon cancer cell lines SW480 and HCT116 were obtained from cell bank of the Chinese Academy of Sciences (Shanghai, PR China). Both cell lines were cultured in RPMI 1640 (GIBCO-BRL, Grand Island, New York, NY, USA) supplemented with $10 \%$ fetal bovine serum (FBS) (Hyclone, Logan, UT, USA) at $37^{\circ} \mathrm{C}$ in $5 \% \mathrm{CO}_{2}$ saturated humidity. si-MyD88 SW480 cells and si-MyD88 HCT116 cells, in which the expression of MyD88 protein is low, were provided by the Key Laboratory of Ministry of Education for Gastrointestinal Cancer, Fujian Medical University (Fuzhou, PR China).

pcDNA3.1-MyD88mut plasmid construction. To rescue MyD88 expression in the MyD88-knockdown (si-MyD88) HCT116 cells, synonymous point mutations were introduced into the shRNA target regions in the full-length MyD88 cDNA. The shRNA-targeted sequence in MyD88 included replacement of a codon for siRNA identification location site. The replacement codon did not change the amino acid that was translated. The shRNA cDNA was subcloned into a pcDNA3.1 vector for translation. The primers were as follows: $M y D 88$ forward: 5'-GGCTAGCGCCACCATGGCTGCAGGAGGTCCC-3', reverse: 5'-GACTCGAGTCAGGGCAGGGACAAGGCCTTG-3', which contained the NheI and XhoI digestion sites, respectively.

$R N A$ preparation, reverse transcription, and quantitative reverse transcription PCR (RT-qPCR). Parental and si-MyD88-transfected SW480 and HCT116 cells were treated with LPS $(1 \mu \mathrm{g} / \mathrm{ml})$ for $48 \mathrm{~h}$. RNA was then extracted by TRIzol Reagent (Invitrogen, Carlsbad, CA, USA) according to the manufacturer's instructions and quantified by UV $260 / 280 \mathrm{~nm}$ at an absorption ratio of $>1.8$. RNA was reverse transcribed to cDNA in a final concentration of $500 \mathrm{ng} / \mu \mathrm{l}$ using the AVM First Strand cDNA synthesis kit (Invitrogen) according to the
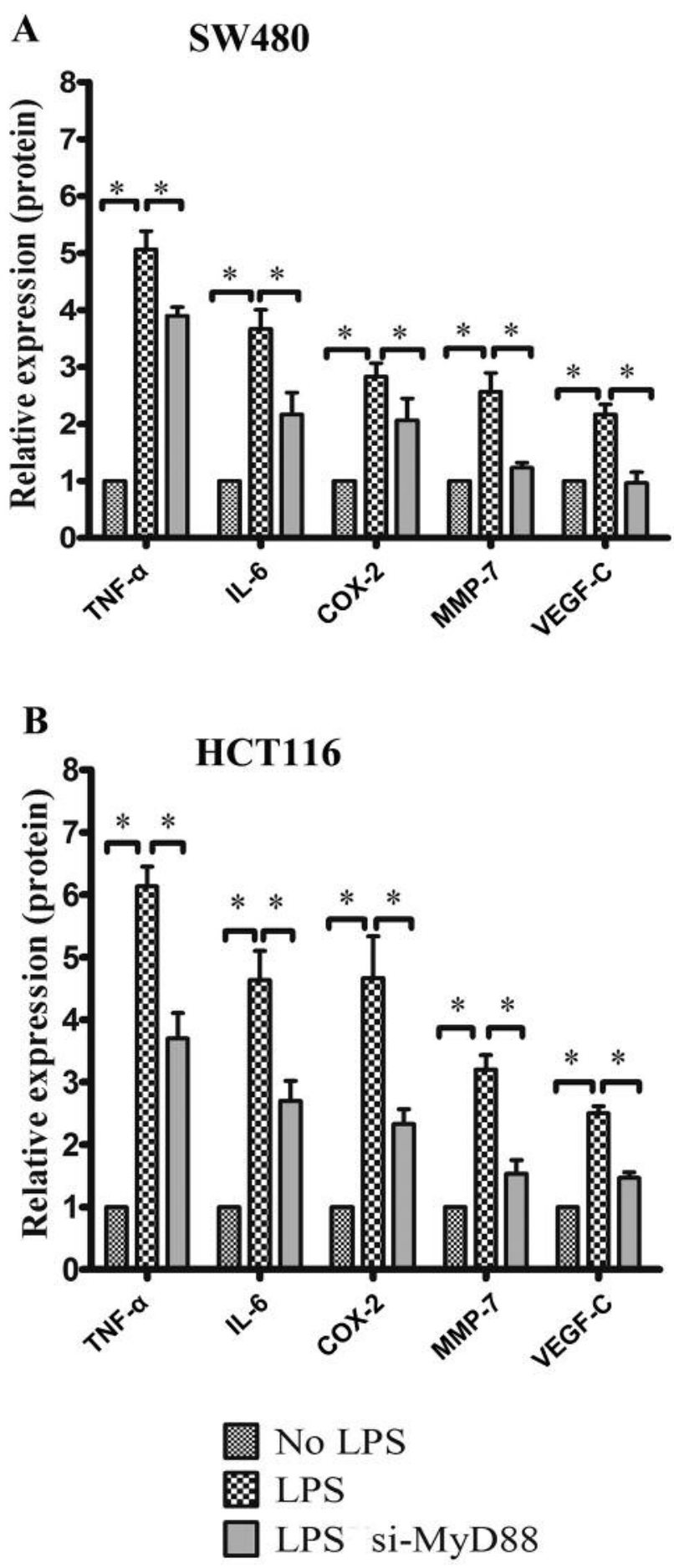

Figure 2. Knockdown of expression of MyD88 with small interfering RNA (si-MyD88) inhibited the protein expression of inflammatory factors induced by lipopolysaccharide (LPS). Expression of tumor necrosis factor- $\alpha$ (TNF-a), interleukin-6 (IL-6), cyclo-oxygenase-2 (COX-2), matrix metallopeptidase-7 (MMP-7), MMP-10, and vascular endothelial growth factor-C (VEGF-C) proteins was assessed in SW480 (A) and HCT116 (B) cells with with/without si-MyD88 after treatment with $1 \mu \mathrm{g}$ LPS for $24 \mathrm{~h}$ and compared to untreated cells. *Significantly different at $p<0.05$. 


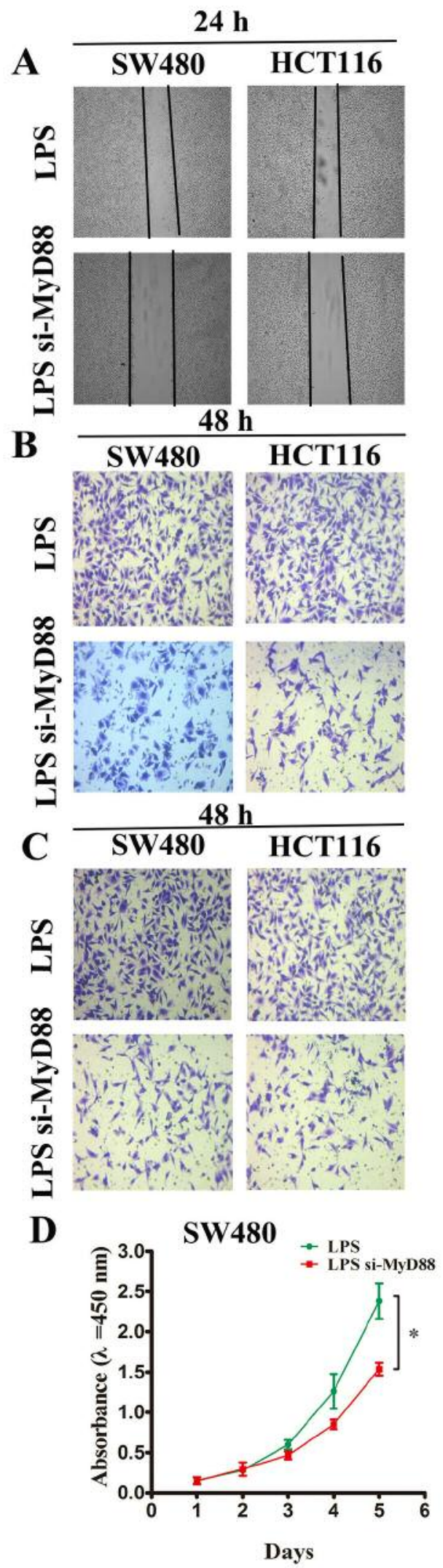

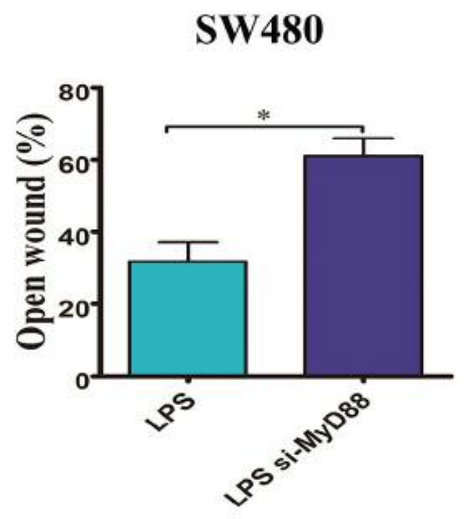
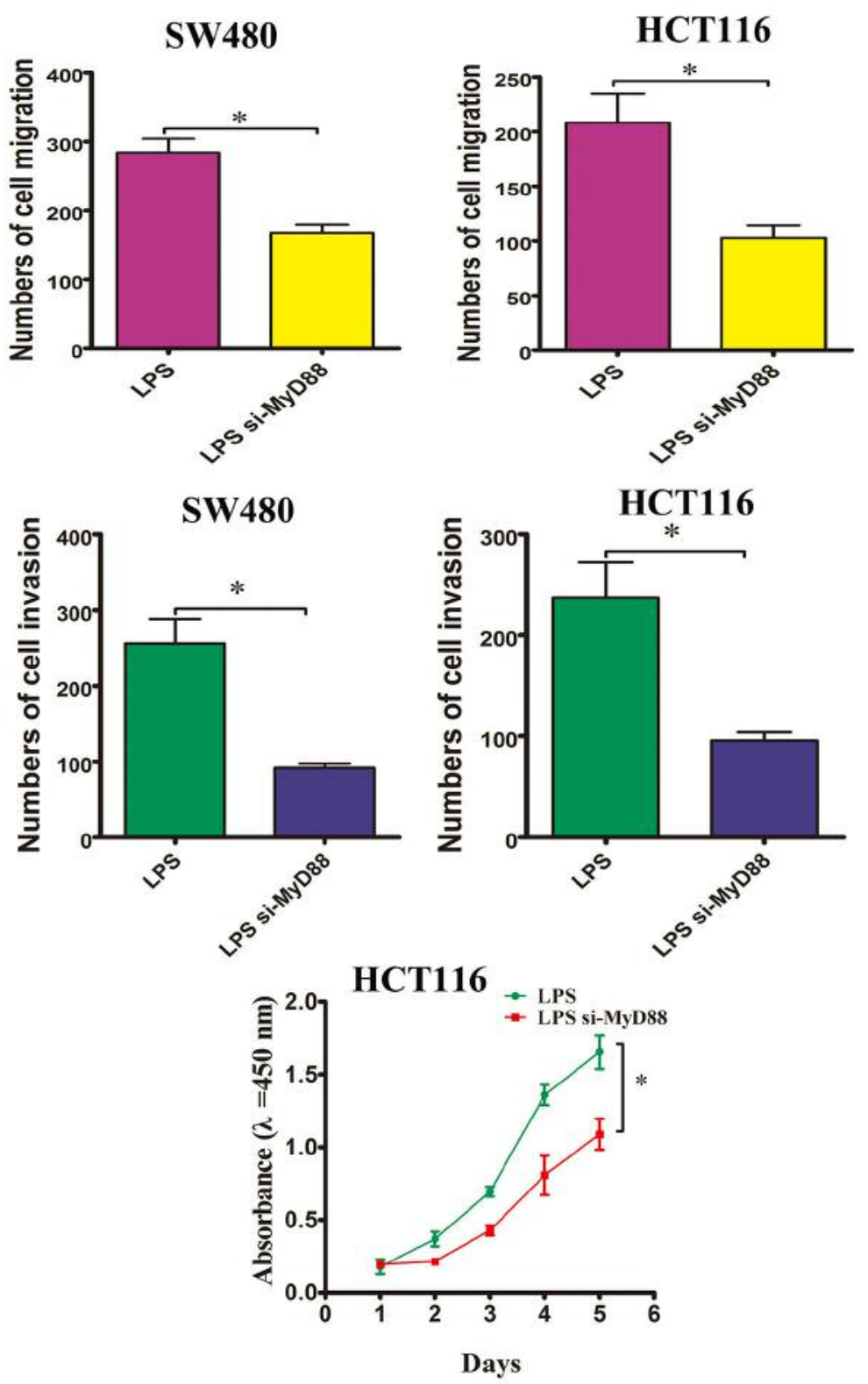

Figure 3. Continued 

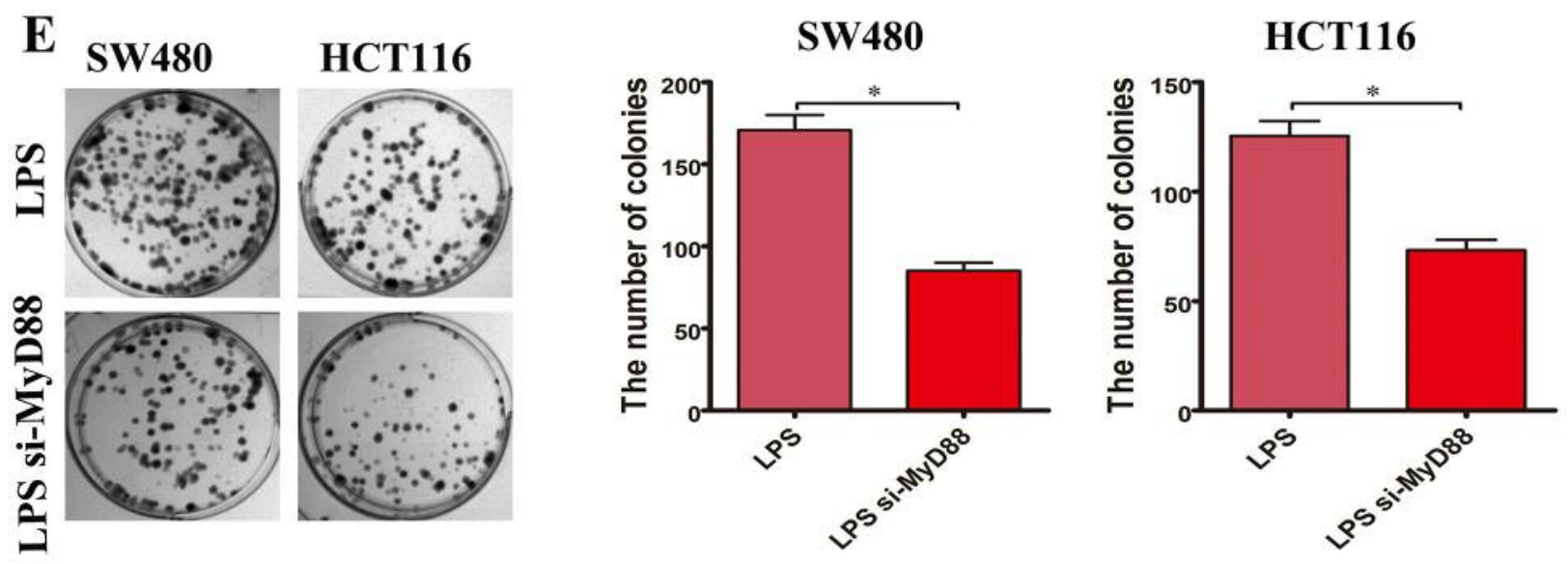

Figure 3. Knockdown of expression of myeloid differentiation 8 with small interfering RNA (si-MyD88) suppressed the growth, migration and invasion of colorectal cancer cells treated with lipopolysaccharide (LPS). Cell migration was assessed by a wound-healing assay at $24 \mathrm{~h}$ (A) and transwell migration assay at $48 h(B)$ in SW480 and HCT116 cells with with/without si-MyD88. C: The cell invasion was detected in the transwell invasion assay (48 h) in SW480, si-MyD88 SW480, HCT116 and si-MyD88 HCT116 cells. CCK-8 cell proliferation assay (D) and colony-formation assay (E) were used to detect the proliferative capacity of $n$ parental and si-MyD88-carrying SW480 and HCT116 cells. *Significantly different at p<0.05.

manufacturer's instructions. qPCR was performed in a $20 \mu \mathrm{l}$ reaction volume with SYBR-Green (Bio-Rad Laboratories, Inc., San Diego, CA, USA) according to the manufacturer's protocols. PCR conditions were $95^{\circ} \mathrm{C}$ for $2 \mathrm{~min}, 95^{\circ} \mathrm{C}$ for $15 \mathrm{~s}$, and $60^{\circ} \mathrm{C}$ for $30 \mathrm{~s}$ for 40 cycles (16). The primer sequences for inflammatory cytokines were as follows: Tumor necrosis factor $(T N F-a)$ forward: 5'CGAGTGACAAGCCTGTAGCC-3', reverse: 5'-TGAAGAGGAC CTGGGAGTAGAT-3'; interleukin-6 (IL-6): forward: 5'-G GAGAC TTGCCTGGTGAA-3', reverse: 5'-GCATTTGTGGTTGGGTC A-3'; cyclo-oxygenase 2 (COX-2): forward: 5'-CCGTCTGAACTATCC TGC -3', reverse: 5'-CGTAGTCGGTGTACT CGTAG-3'; matrix metallopeptidase-7 (MMP-7): forward: 5'-GACTCCTACCCAT TTGATG-3', reverse: 5'-AAGTTAATCCCTAGACT GCTA-3'; vascular endothelial growth factor $\mathrm{C}(V E G F-C)$ : forward: 5'-GGGG AAGGAGTTTGGAGT-3', reverse: 5'-GGTAGCTCGTGCTGG TGT-3'. Glyceraldehyde 3-phosphate dehydrogenase (GAPDH) was used as an endogenous control (primer sequences: forward: 5'ACCAGGGCTGCTTTTAAC-3' and reverse: 5'-ACGGTGCCA

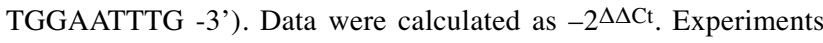
were repeated three times.

Western blot analysis. Cells were lysed with western IP cell lysis buffer (Beyotime Institute of Biotechnology, Shanghai, PR China) containing phenylmethylsulfonyl fluoride (Amresco, LLC, Cochran Solon, OH, USA) on ice for $30 \mathrm{~min}$. Equal amounts of protein (25 $\mu \mathrm{g}$ / lane) were separated by sodium dodecyl sulfate polyacrylamide gel electrophoresis on $10 \%$ gel electrophoresis and transferred onto $0.45 \mu \mathrm{m}$ polyvinylidene membranes (GE Healthcare Life Sciences, Pittsburgh, PA, USA). Bovine serum album (0.5\%; Amresco, LLC) was used at room temperature for $2 \mathrm{~h}$ to block the membranes (17, 18). The following monoclonal primary antibodies were used for western blot analysis overnight at $4^{\circ} \mathrm{C}$ : anti-MyD88 (1:1000; Affinity, Biosciences, OH, USA), anti-GAPDH (1:1000; Abcam, Cambridge, MA, USA), anti-NF-kB (1:1000; Affinity), anti-phosphorylated (p)NF-кB (1:1000; Abcam), anti-inhibitor of nuclear factor-кB $\alpha$
(IkB $\alpha)(1: 1000 ;$ Abcam), anti-pIkB $\alpha$ (1:1000; Abcam), anti-phosphoextracellular regulated kinase (pERK) (1:1000; Bioss, Beijing, China) and anti-phosphorylated c-Jun $N$-terminal kinase (pJNK) (1:1000; Bioss). The membranes were washed three times with Tris-buffered saline with $0.1 \%$ Tween 20 for $10 \mathrm{~min}$ each at room temperature. The membranes were incubated with anti-rabbit immunoglobulin IgG and mouse IgG (both 1:4000; both from Santa Cruz Biotechnology, Inc., Santa Cruz, CA, USA) horseradish peroxidase-conjugated secondary antibodies at room temperature for $1 \mathrm{~h}$. The signal was visualized with chemiluminescence kit (BeyoECL Plus; Beyotime Institute of Biotechnology). The intensities of band signals were quantified using Quantified One densitometric software (Bio-Rad Laboratories, Inc.). The relative intensity of the target bands was normalized to that of GAPDH. Experiments were repeated three times.

Enzyme-linked immunosorbent assay (ELISA). SW480, HCT116, siMyD88 SW480 and si-MyD88 HCT116 cells were seeded in 6-well plates and incubated in RPMI 1640 with $10 \%$ FBS. The colorectal cancer cells were treated with $1 \mu \mathrm{g}$ LPS (Escherichia coli 055:B5) for $48 \mathrm{~h}$. The amounts of TNF- $\alpha$, IL-6, COX-2, MMP-7, and VEGF-C in colorectal cancer cell culture supernatants were quantified with ELISA (Wuhan Boster Biological Technology, Ltd., Wuhan, PR China) according to the manufacturer's instructions. Each plate test was repeated three times.

Wound-healing assay. Cells (si-MyD88 SW480, si-MyD88 HCT116 and si-MyD88-MyD88mut cells) were seeded onto 6-well plates with $1 \mu \mathrm{g}$ LPS added when cell convergence reached $100 \%$. Wounds were scratched on the monolayer cells using $20 \mu$ pipette tips. The plates were photographed $24 \mathrm{~h}$ after seeding in FBS-free RPMI 1640. Experiments were repeated three times.

Cell migration and invasion assay. Transwell chambers (24-well format; FALCON) with Matrigel-coating chambers (BD Bioscience, Franklin Lake, NJ, USA) were inserted into 24-well cell culture plates 


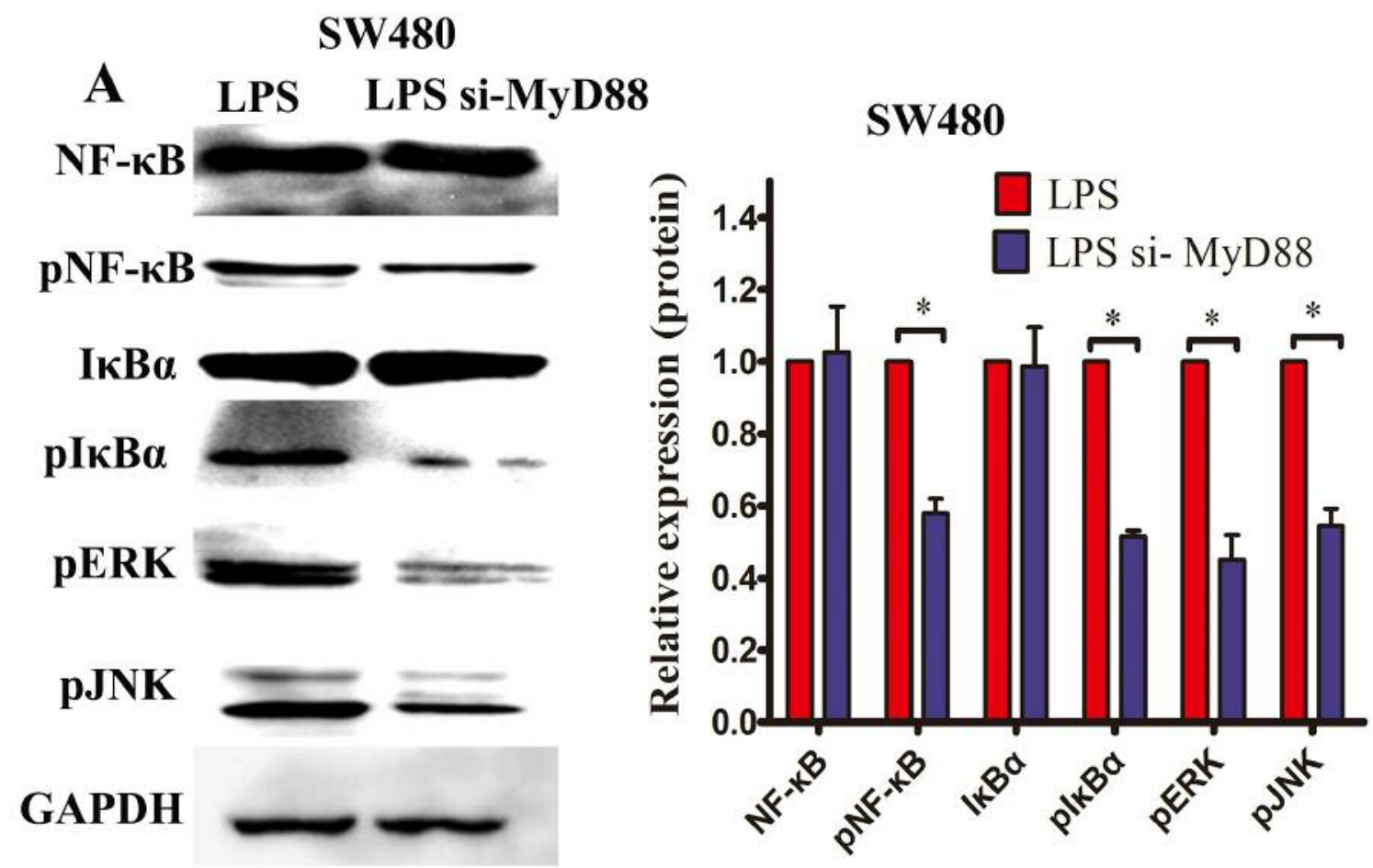

HCT116

B LPS LPS si-MyD88

NF-кB

HCT116
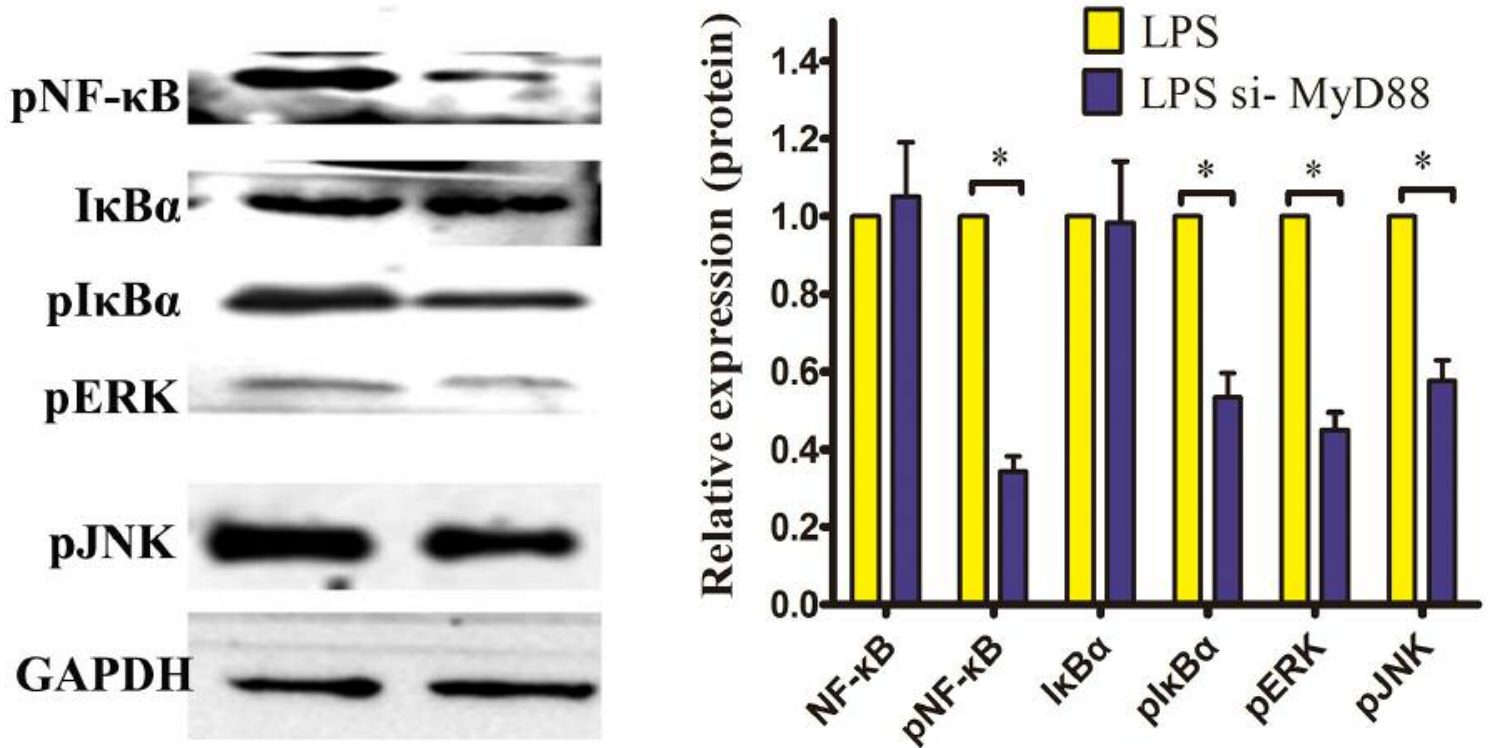

Figure 4. Knockdown of expression of MyD88 with small interfering RNA (si-MyD88) down-regulated the protein expression of the lipopolysaccharide (LPS)/nuclear factor kappa-light-chain-enhancer of activated B-cells (NF-kB)/mitogen-activated protein kinase (MAPK) signaling pathway. Expression of $N F-k B$, phospho-( $p) N F-k B$, inhibitor of nuclear factor- $k B \alpha($ I $k B \alpha), p I k B \alpha$, phospho-extracellular regulated kinase ( $p E R K$ ) and phospho-c-Jun N-terminal kinase (pJNK) protein was assessed in parental and si-MyD88-carrying SW480 (A) and HCT116 (B) cells by western blot (left panel) and the results were quantified (right panel). *Significantly different at $p<0.05$. 
to measure migration and invasion with addition of $1 \mu \mathrm{g}$ LPS. Cells ( $10^{5}$ in $0.3 \mathrm{ml}$ serum-free medium) were added to the upper chamber, with $800 \mu$ l of RPMI 1640 containing FBS (10\%) added to the lower chamber. Colorectal cancer cells were cultured for $48 \mathrm{~h}$. Then cells in the transwell chambers were fixed in methanol for $5 \mathrm{~min}$ and stained with crystal violet and counted in three random fields under a microscope. Experiments were repeated three times.

Colony formation assay. Colorectal cancer cells were seeded onto 6-well plates at a density of 500 cells per well with $1 \mu \mathrm{g}$ LPS and cultured for 2 weeks. Methanol was used to fix the cells for $10 \mathrm{~min}$ and crystal violet was used to stain the cells. Colonies of 50 or more cells were then counted. Experiments were repeated three times.

Cell proliferation assay. Colorectal cancer cells were seeded in 96well plates at a density of 1,500 per well, with three replicates for each experimental group. The cells were cultured in FBS-containing medium with $1 \mu \mathrm{g}$ LPS and placed in an incubator with $5 \% \mathrm{CO}_{2}$ at $37^{\circ} \mathrm{C}$ for $1,2,3,4,5$ days, and CCK-8 (Cell Counting Kit-8, Dojindo, Kumamoto, Japan) after the old medium was replaced with serum-free medium, cells were counted with microplate reader (BioTek, Winooski, VT, USA). Experiments were repeated three times.

Statistical analysis. All statistical analyses were performed using GraphPad Prism 5 software (GraphPad Software, Inc., La Jolla, CA, USA). Data were analyzed by ANOVA with Tukey's post-hoc test when more than two groups were compared or Student's t-test when two groups were compared. The data are expressed as the mean \pm standard deviation. A value of $p<0.05$ indicates a statistical significance.

\section{Results}

Knockdown of MyD88 expression down-regulated the mRNA expression of inflammatory cytokines induced by LPS. SW480 and HCT116 cells were used to investigate the effect of LPS on the mRNA expression of inflammatory cytokines. Using RT-qPCR, the mRNA expression of $T N F-a, I L-6$, $C O X-2, M M P-7$, and VEGF-C in the SW480 and HCT116 cells, which were treated with $1 \mu \mathrm{g}$ LPS in the culture medium for $24 \mathrm{~h}$ was quantified. The $T N F-a, I L-6, C O X-2$, $M M P-7$ and $V E G F-C$ mRNA expression in the LPS-treated SW480 and HCT116 cells was higher than the untreated control SW480 and HCT116 cells $(p<0.05$; Figure 1A). Western blot analysis of MyD88 protein expression levels showed that MyD88 protein expression was inhibited in the si-MyD88-carrying SW480 and HCT116 cells compared with in the control cell lines ( $p<0.05$; Figure 1B). For cells not treated with LPS, TNF- $a, I L-6, C O X-2, M M P-7$ and $V E G F-C$ mRNA expression was significantly lower compared with SW480 and HCT116 cells that were treated with $1 \mu \mathrm{g}$ LPS $(p<0.05$; Figure 1C).

Knockdown of MyD88 expression inhibited the protein expression of inflammatory cytokines induced by LPS. Using an ELISA assay, TNF- $a, I L-6, C O X-2, M M P-7$ and VEGF-C protein expression in SW480 and HCT116 cells treated with
A
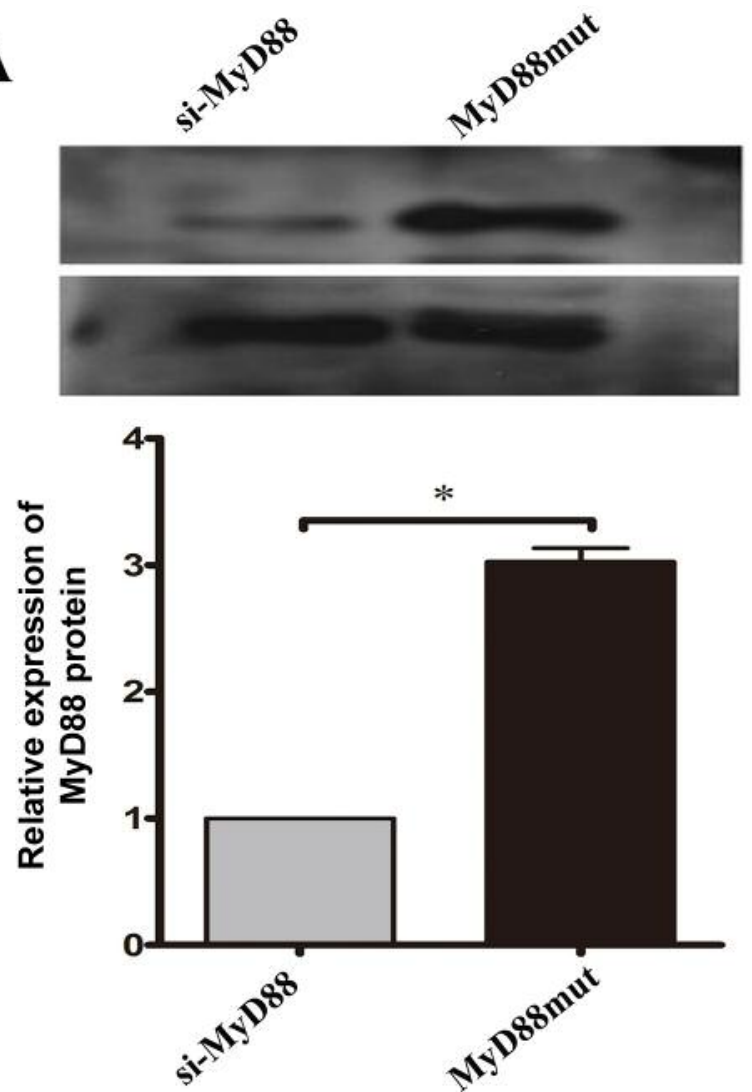

B

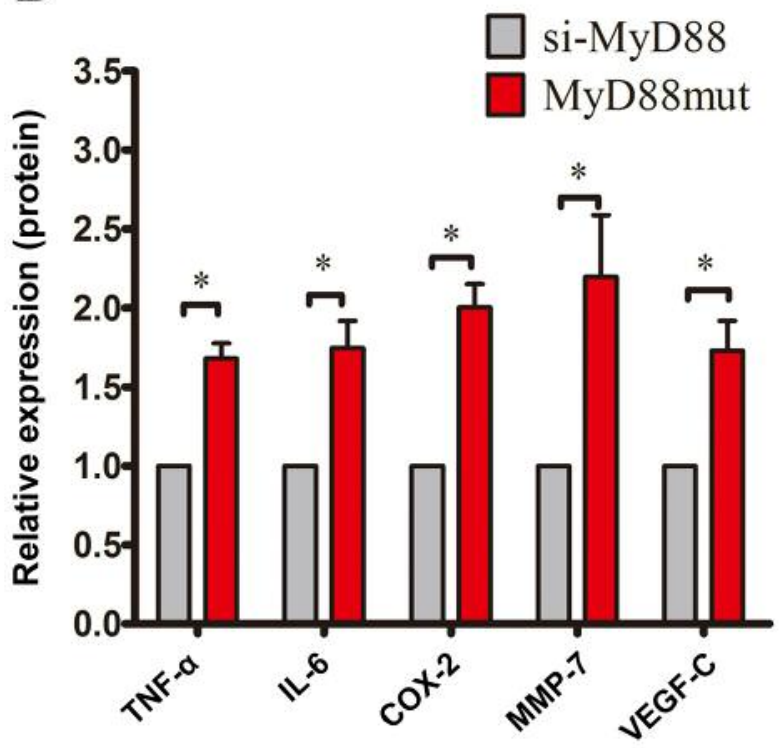

Figure 5. Expression of inflammatory factors after restoration of expression of myeloid differentiation 88 (MyD88 mut) in lipopolysaccharide (LPS)treated HCT116 cells with MyD88-knockdown (si-MyD88). A: MyD88 protein expression as detected by western blot analysis. B: Tumor necrosis factor- $\alpha$ (TNF-a), interleukin-6 (IL-6), cyclo-oxygenase-2 (COX-2), matrix metallopeptidase-7 (MMP-7), and vascular endothelial growth factor-C (VEGF-C) protein expression as assessed by enzyme-linked immunosorbent assay (ELISA). 
A
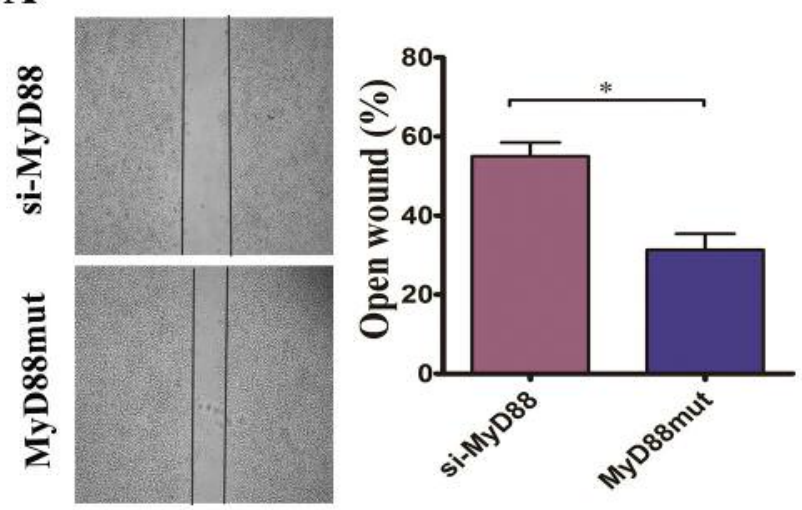

C
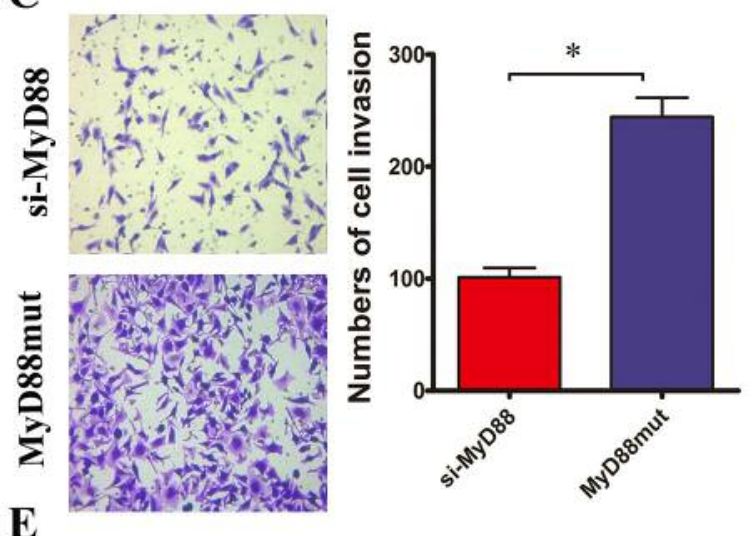

$\mathbf{E}$

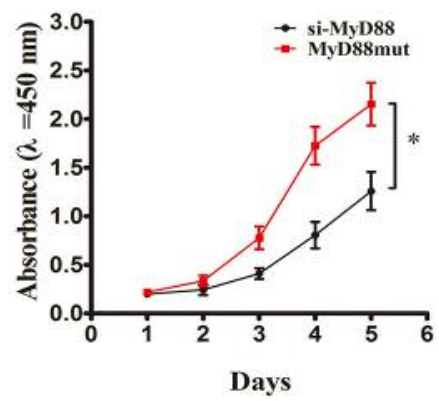

LPS was higher than that in the untreated cells. Cytokine expression was significantly suppressed in the si-MyD88carrying SW480 and HCT116 cells compared with parental cells $(p<0.05$; Figure 2$)$.

Knockdown of MyD88 expression suppressed the growth, migration and invasion of colorectal cancer cells treated with LPS. Wound healing and migration of LPS-treated siMyD88-carrying cells was significantly lower than LPStreated parental SW480 and HCT116 cells $(p<0.05$; Figures
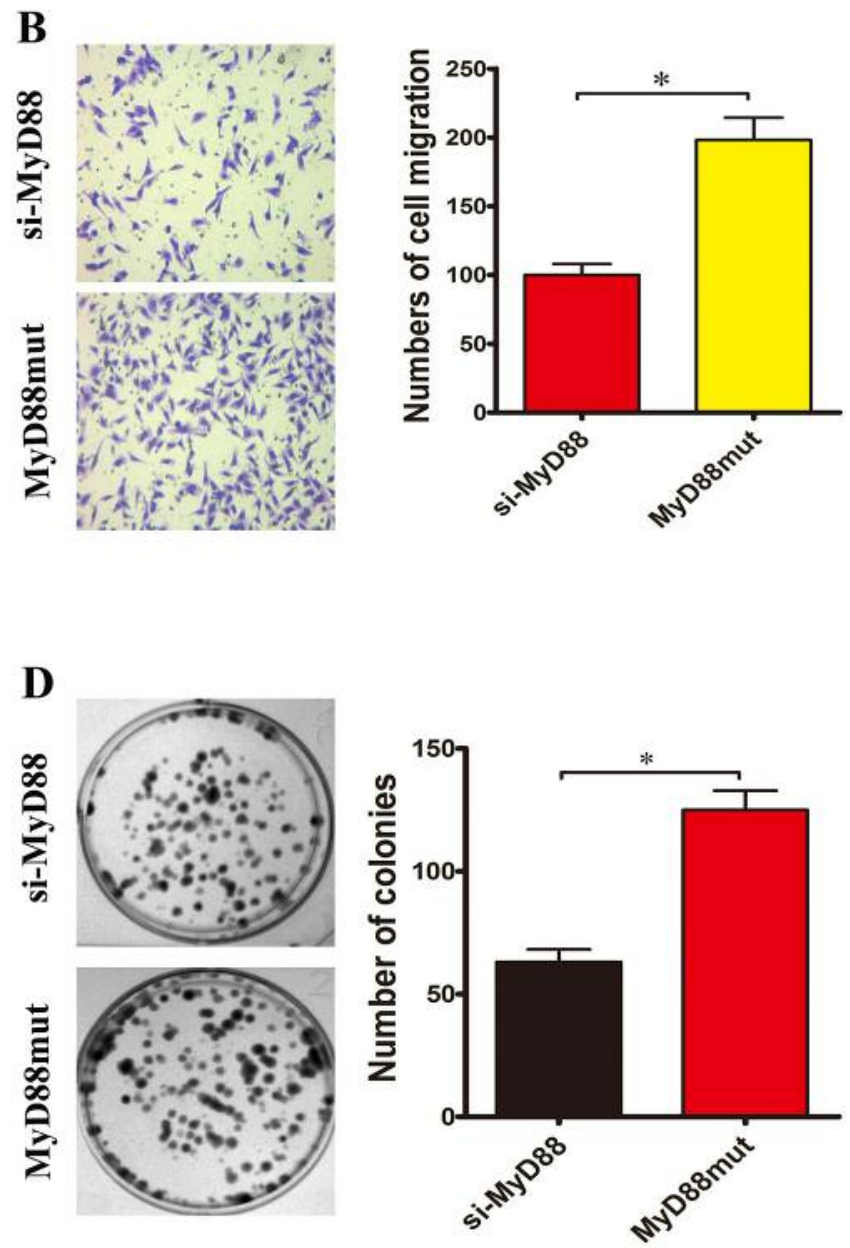

Figure 6. Effect of restoration of MyD88-mut-expression on migration, invasion, proliferation, and colony formation of lipopolysaccharide (LPS)-treated HCT116 cells with MyD88-knockdown (si-MyD88). A: Wound-healing assay at $24 \mathrm{~h}$. B: Transwell migration assay at $48 \mathrm{~h}$. C: Invasion was assessed by transwell invasion assay at 48 h. D: Colonyformation E: CCK-8 cell proliferation assay of HCT116 cells. *Significantly different at $p<0.05$.

3A-C). The effect of si-MyD88 knockdown on cell growth was assessed by cell colony formation and cell proliferation. Cell proliferation and colony formation LPS-treated siMyD88 SW480 and si-MyD88 HCT116 cells was significantly reduced compared to LPS-treated parental cells $(p<0.05$; Figures $3 \mathrm{E}$ and D).

Knockdown of MyD88 expression down-regulated the protein expression of members of the LPS/NF-kB/mitogen-activated protein kinase (MAPK) signaling pathway. To investigate the 

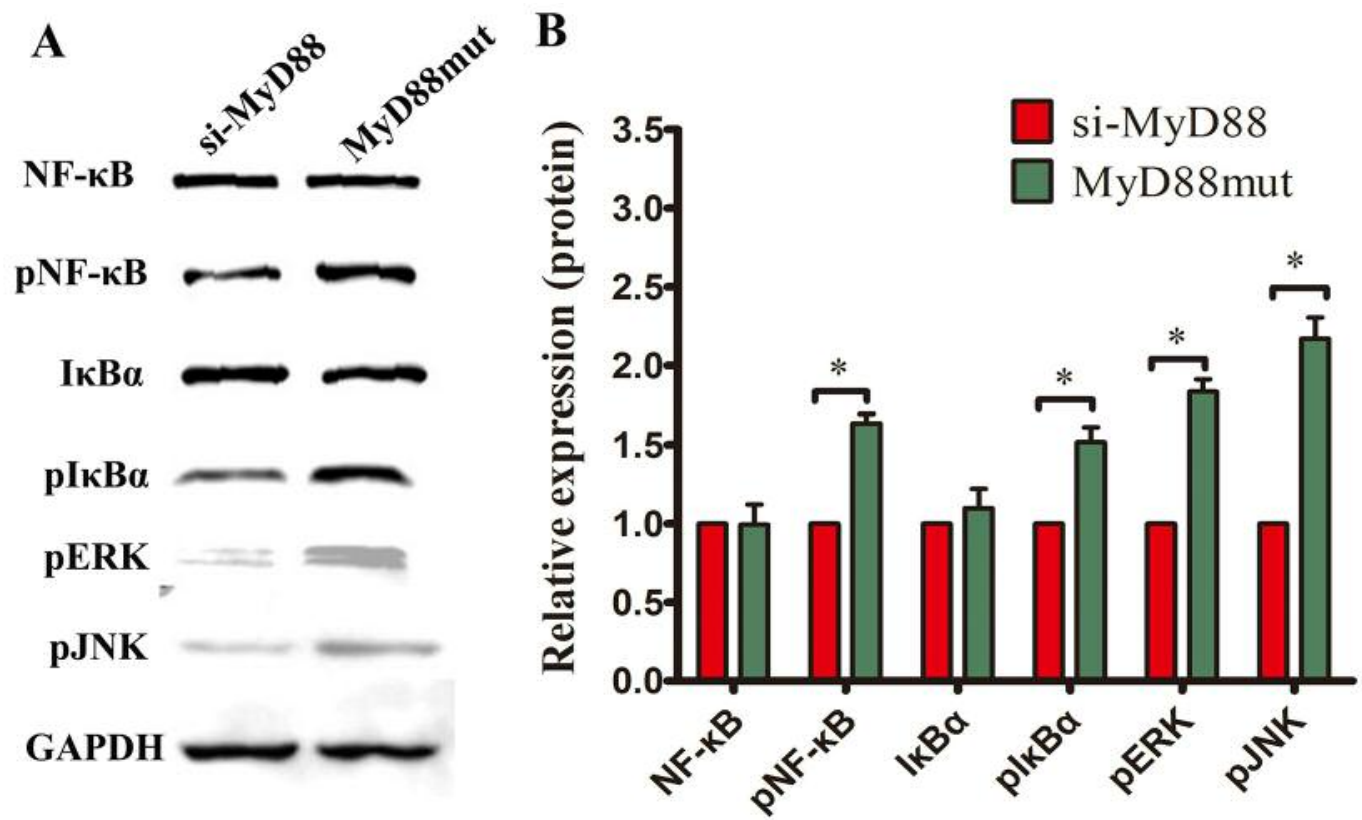

Figure 7. Expression of proteins of the lipopolysaccharide (LPS)-myeloid differentiation 88 (MyD88) signaling pathway after restoration of MyD88 (MyD88 mut) in HCT116 cells with MyD88-knockdown (si-MyD88). A: Expression of nuclear factor kappa-light-chain-enhancer of activated $B$-cells $(N F-k B)$, phospho-( $p) N F-\kappa B$, inhibitor of nuclear factor- $k B \alpha(I k B \alpha), p I k B \alpha$, phospho-extracellular regulated kinase ( $p E R K)$ and phosphoc-Jun N-terminal kinase (pJNK) proteins was assessed in LPS-treated si-MyD88 and si-MyD88-MyD88mut HCT116 cells by western blot. B: Quantification of the results from (A). GAPDH: glyceraldehyde 3-phosphate dehydrogenase. *Significantly different at $p<0.05$.

effect of LPS on the MyD88 signaling pathway, we assessed the protein expression of NF-kB, pNF-кB, IкB $\alpha, \mathrm{pI \kappa B} \alpha$, pERK and pJNK, which are vital to the LPS-MyD88 signaling pathway. Western blot analysis demonstrated that pNF-кB, pIkB $\alpha, p E R K$ and pJNK protein levels in LPStreated si-MyD88-carrying SW480 and HCT116 cells decreased in comparison to LPS-treated parental cells $(p<0.05$; Figure 4).

Restoring the MyD88 expression increased the expression of inflammatory factors, migration, invasion and proliferation of si-MyD88 HCT116 cells. To confirm the specificity of the effect of MyD88 knockdown on the biological behavior of HCT116 cells, MyD88 expression was restored in the si-MyD88 HCT116 cells by transfecting them with a pcDNA3.1-MyD88mut vector expressing MyD88 mRNA that had been mutated to prevent the shRNA from causing knockdown $(p<0.05$; Figure 5A). As expected, re-expression of MyD88 in the si-MyD88 HCT116 cells increased the expression of inflammatory factors including TNF- $\alpha$, IL-6, COX-2, MMP-7, and VEGF-C proteins $(p<0.05$; Figure $5 \mathrm{~B})$. Re-expression of MyD88 in the si-MyD88 HCT116 cells increased the cell migration ( $p<0.05$; Figure 6$)$, invasion $(p<0.05$; Figure $5 \mathrm{C})$ and proliferation $(p<0.05$; Figure $5 \mathrm{D}$ and $\mathrm{E})$.
Restoring MyD88 expression in si-MyD88 HCT116 cells restored the protein expression of the LPS/NF- $k B / M A P K$ signaling pathway. To investigate the LPS-MyD88 signaling pathway changes in the si-MyD88 HCT116 and si-MyD88MyD88mut HCT116 cells after LPS treatment, we assessed the protein expression of NF-kB, $\mathrm{pNF}-\mathrm{kB}, \mathrm{IkB} \alpha, \mathrm{pI} \mathrm{BB} \alpha$, pERK and pJNK in these colorectal cancer cells. Western blot analysis indicated that the pNF-kB, $\mathrm{pIkB} \alpha, \mathrm{pERK}$ and pJNK proteins levels in LPS-treated si-MyD88-MyD88mut HCT116 cells increased in comparison to LPS-treated siMyD88 HCT116 cells ( $p<0.05$; Figure 7).

\section{Discussion}

LPS is a strong stimulator of microglial activation, which can increase the expression of inflammatory factors such as MyD88, IL-6 and IL-10 in cancer cells thus causing an inflammatory response. Previous studies also found LPS increased the expression of inflammatory factors in cancer cells $(19,20)$. The LPS-MyD88-dependent signaling pathway comprising pro-inflammatory genes which encode regulators promoting tumorigenesis $(21,22)$. MyD88 is an essential adaptor molecule for IL-1 and toll-like receptor signaling (23). In this study, we demonstrated that LPS can increase the expression of $T N F-\alpha, I L-6, C O X-2, M M P-7$, and 
$V E G F-C$ mRNA and protein, and that MyD88 can regulate this signaling pathway of inflammatory factors induced by LPS in colorectal cancer cells.

$\mathrm{Yu}$ et al. demonstrated that LPS can recruit MyD88 causing changes in its downstream signaling pathway (24). Yang et al. found that LPS can trigger the activation of MyD88 subsequently triggering NF-kB and MAPK signaling pathways (25). To explore whether MyD88 can cause changes in LPS-induced pathways, we performed a series experiments to detect the changes. Silencing of MyD88 in SW480 and HCT116 cells inhibited the increased migration, invasion and proliferation after treatment with LPS. These studies indicated that LPS-MyD88 signaling-induced inflammation may participate in the progression of human colorectal cancer cells, consistent with Zhang et al. (26), who had reported that knockdown of MyD88 can reduce LPS-induced expression of inflammatory factors (26). We further demonstrated the role of MyD88 in LPS-promoted expression of inflammatory cytokines and migration, invasion, and proliferation in colorectal cancer cells. By restoring MyD88 expression in si-MyD88 HCT116 cells, we found that LPS-promoted expression of inflammatory factors, and cell migration and cell invasive ability and proliferative capacity were also restored. These results indicate MyD88 plays an important role in the LPS-induced pathway, which can affect the biological behavior of colorectal cancer cells.

How LPS-induced pathways react is not fully understood. Previous studies have reported that NF-kB/MAPK is very important in the MyD88 signaling pathway induced by LPS (26-28). The NF-kB/MAPK signaling pathway plays important roles in inflammatory responses. Therefore, we performed experiments to confirm whether MyD88 causes changes in the expression in LPS/NF-kB/MAPK signaling pathway (25). Western blot analysis indicated that $\mathrm{pNF}-\mathrm{kB}$, $\mathrm{pIkB} \alpha, \mathrm{pERK}$ and pJNK protein levels in LPS-treated siMyD88 SW480 and si-MyD88 HCT116 cells decreased in comparison to LPS-treated parental cells. In addition, we restored MyD88 in si-MyD88 HCT116 cells and found that the $\mathrm{pNF}-\mathrm{kB}, \mathrm{pIkB} \alpha, \mathrm{pERK}$ and $\mathrm{pJNK}$ protein levels were also restored.

In conclusion, the present study revealed that LPS can promote the expression of inflammation-related genes in SW480 and HCT116 cells. Knockdown of MyD88 expression reduced this expression and reduced the malignant behavior of SW480 and HCT116 cells. Our study suggests that MyD88 may regulate the LPS-induced NF$\mathrm{KB} / \mathrm{MAPK}$ signaling pathway and might be used as a novel biomarker in the treatment of colorectal cancer.

\section{Conflicts of Interest}

The Authors declare no conflicts of interest regarding this study.

\section{Author's Contributions}

GZ and JY designed the study, modified the figures and wrote the draft article; GZ, ZC and CL performed the experiments; YH, WZ and SY analyzed the data, prepared the draft figures; SRS and RMH revised the article. All Authors approved the final article.

\section{Acknowledgements}

This study was supported by the National Natural Science Foundation of China (no. 81702424 and 81872364), The Fujian Provincial Health Department Young and Middle-aged Talents Training Project (no. 2018-ZQN-46), The Joint Funds for the Innovation of Science and Technology, Fujian Province (no. 2017Y9092), The Project of Science and Technology Research Program in Fujian Province (no. 2016B044), The Fujian Provincial Natural Science Foundation (no. 2018J05127), the National Clinical Key Specialty Construction Project (General Surgery) of China.

\section{References}

1 Chen W, Zheng R, Baade PD, Zhang S, Zeng H, Bray F, Jemal A, Yu XQ and He J: Cancer statistics in China, 2015. CA Cancer J Clin 66: 115-132, 2016. PMID: 26808342. DOI: 10.3322/ caac. 21338

2 Jemal A, Siegel R, Ward E, Hao Y, Xu J and Thun MJ: Cancer statistics, 2009. CA Cancer J Clin 59: 225-249, 2009. PMID: 19474385. DOI: $10.3322 /$ caac.20006

3 Mantovani A, Allavena P, Sica A and Balkwill F: Cancer-related inflammation. Nature 454: 436-444, 2008. PMID: 18650914. DOI: 10.1038 /nature07205

4 Bryant T: Remarks on some cases of inflammation of the breast simulating cancer. $\mathrm{Br}$ Med J 2: 608-609, 1868. PMID: 20745348. DOI: $10.1136 / \mathrm{bmj} .2 .415 .608$

5 Coussens LM and Werb Z: Inflammation and cancer. Nature 420: 860-867, 2002. PMID: 12490959. DOI: 10.1038/nature01322

6 Compare D and Nardone G: Contribution of gut microbiota to colonic and extracolonic cancer development. Dig Dis 29: 554561, 2011. PMID: 22179211. DOI: 10.1159/000332967

7 Mima K, Nishihara R, Qian ZR, Cao Y, Sukawa Y, Nowak JA, Yang J, Dou R, Masugi Y, Song M, Kostic AD, Giannakis M, Bullman S, Milner DA, Baba H, Giovannucci EL, Garraway LA, Freeman GJ, Dranoff G, Garrett WS, Huttenhower C, Meyerson M, Meyerhardt JA, Chan AT, Fuchs CS and Ogino S: Fusobacterium nucleatum in colorectal carcinoma tissue and patient prognosis. Gut 65: 1973-1980, 2016. PMID: 26311717. DOI: 10.1136/gutjnl-2015-310101

8 Liu X, Liang J and Li G: Lipopolysaccharide promotes adhesion and invasion of hepatoma cell lines HepG2 and HepG2.2.15. Mol Biol Rep 37: 2235-2239, 2010. PMID: 19680784. DOI: 10.1007/s11033-009-9710-4

9 Huang T, Chen Z and Fang L: Curcumin inhibits LPS-induced EMT through downregulation of NF-kappaB-SNAIL signaling in breast cancer cells. Oncol Rep 29: 117-124, 2013. PMID: 23076367. DOI: 10.3892/or.2012.2080

10 Zhao L, Yang R, Cheng L, Wang M, Jiang Y and Wang S: LPSinduced epithelial-mesenchymal transition of intrahepatic biliary epithelial cells. J Surg Res 171: 819-825, 2011. PMID: 20691985. DOI: 10.1016/j.jss.2010.04.059 
11 McMillan DC, Canna K and McArdle CS: The effect of deprivation and the systemic inflammatory response on outcome following curative resection for colorectal cancer. Br J Cancer 89: 612-614, 2003. PMID: 12915865. DOI: 10.1038/sj.bjc.6601156

12 Eberhardt JM, Kiran RP and Lavery IC: The impact of anastomotic leak and intra-abdominal abscess on cancer-related outcomes after resection for colorectal cancer: A case-control study. Dis Colon Rectum 52: 380-386, 2009. PMID: 19333035. DOI: 10.1007/DCR.0b013e31819ad488

$13 \mathrm{Yu} \mathrm{L}$ and Chen S: Toll-like receptors expressed in tumor cells: Targets for therapy. Cancer Immnol Immunother 57: 1271-1278, 2008. PMID: 18256828. DOI: 10.1007/s00262-008-0459-8

14 Kawai $\mathrm{T}$, Adachi O, Ogawa $\mathrm{T}$, Takeda $\mathrm{K}$ and Akira S: Unresponsiveness of MyD88-deficient mice to endotoxin. Immunity 11: 115-122, 1999. PMID: 10435584.

15 Hoesel B and Schmid JA: The complexity of NF-kappaB signaling in inflammation and cancer. Mol Cancer 12: 86, 2013. PMID: 23915189. DOI: 10.1186/1476-4598-12-86

16 Zhu G, Ye J, Huang Y, Zheng W, Hua J, Yang S, Zhuang J and Wang J: Receptor-interacting protein-1 promotes the growth and invasion in gastric cancer. Int J Oncol 48: 2387-2398, 2016 PMID: 27035122. DOI: 10.3892/ijo.2016.3455

17 Zhu G, Chen X, Wang X, Li X, Du Q, Hong H, Tang N, She F and Chen Y: Expression of the RIP-1 gene and its role in growth and invasion of human gallbladder carcinoma. Cell Physiol Biochem 34: 1152-1165, 2014. PMID: 25277242. DOI: $10.1159 / 000366328$

18 Zhu G, Du Q, Wang X, Tang N, She F and Chen Y: TNF-alpha promotes gallbladder cancer cell growth and invasion through autocrine mechanisms. Int J Mol Med 33: 1431-1440, 2014 PMID: 24676340. DOI: 10.3892/ijmm.2014.1711

19 Wang L, Lan XY, Ji J and Zhang CF: Anti-inflammatory and anti-angiogenic activities in vitro of eight diterpenes from Daphne genkwa based on hierarchical cluster and principal component analysis. J Nat Med 72: 675-685, 2018. PMID: 29680963. DOI: 10.1007/s11418-018-1202-1

$20 \mathrm{Li} \mathrm{D}$, Xiao Z, Wang G and Song X: Knockdown of ADAM10 inhibits migration and invasion of fibroblast-like synoviocytes in rheumatoid arthritis. Mol Med Rep 12: 5517-5523, 2015. PMID: 26135838. DOI: 10.3892/mmr.2015.4011

21 Oshima H, Oshima M, Kobayashi M, Tsutsumi M and Taketo MM: Morphological and molecular processes of polyp formation in Apc(delta716) knockout mice. Cancer Res 57: 1644-1649, 1997. PMID: 9135000.

22 Chulada PC, Thompson MB, Mahler JF, Doyle CM, Gaul BW, Lee C, Tiano HF, Morham SG, Smithies O and Langenbach R: Genetic disruption of Ptgs-1, as well as Ptgs-2, reduces intestinal tumorigenesis in Min mice. Cancer Res 60: 4705-4708, 2000. PMID: 10987272.
23 Lingel A, Ehlers E, Wang Q, Cao M, Wood C, Lin R and Zhang L: Kaposi's sarcoma-associated herpesvirus reduces cellular myeloid differentiation primary-response gene 88 (MyD88) expression via modulation of its RNA. J Virol 90: 180-188, 2016. PMID: 26468534. DOI: 10.1128/JVI.02342-15

24 Yu J, Guo M, Li Y, Zhang H, Chai Z, Wang Q, Yan Y, Yu J, Liu $\mathrm{C}$, Zhang $\mathrm{G}$ and Cungen $\mathrm{M}$ : Astragaloside IV protects neurons from microglia-mediated cell damage through promoting microglia polarization. Folia Neuropathol 57(2): 170-181, 2019. PMID: 31556576. DOI: 10.5114/fn.2019.86299

25 Yang H, Wang B, Wang T, Xu L, He C, Wen H, Yan J, Su H and Zhu $\mathrm{X}$ : Toll-like receptor 4 prompts human breast cancer cells invasiveness via lipopolysaccharide stimulation and is overexpressed in patients with lymph node metastasis. PloS One 9: e109980, 2014. PMID: 25299052. DOI: 10.1371/journal.pone.0109980

26 Zhang J, Zheng Q, Lu H, Jin F, Li Y, Bi F and $\mathrm{Xu} \mathrm{J:}$ Notoginsenoside R1 protects human keratinocytes $\mathrm{HaCaT}$ from LPS-induced inflammatory injury by downregulation of Myd88. Int J Immunopathol Pharmacol 33: 2058738419857550, 2019. PMID: 31204533. DOI: 10.1177/2058738419857550

27 Haque MA, Jantan I, Harikrishnan H and Ghazalee S: Standardized extract of Zingiber zerumbet suppresses LPSinduced pro-inflammatory responses through NF-kappaB, MAPK and PI3K-AKT signaling pathways in U937 macrophages. Phytomedicine 54: 195-205, 2019. PMID: 30668369. DOI: 10.1016/j.phymed.2018.09.183

28 Harikrishnan $\mathrm{H}$ and Jantan I: Phyllanthin from Phyllanthus amarus inhibits LPS-induced proinflammatory responses in U937 macrophages via downregulation of NF-kappaB/ MAPK/PI3K-Akt signaling pathways. Phytother Res 32: 25102519, 2018. PMID: 30238535. DOI: 10.1002/ptr.6190

29 Shang L, Wang T, Tong D, Kang W, Liang Q and Ge S: Prolyl hydroxylases positively regulated LPS-induced inflammation in human gingival fibroblasts via TLR4/MyD88-mediated AKT/NF-kappaB and MAPK pathways. Cell Prolif 51(6): e12516, 2018. PMID: 30091492. DOI: 10.1111/cpr.12516
Received August 27, 2019

Revised October 1, 2019

Accepted October 4, 2019 